\title{
Ball-Joint Wireless Power Transfer Systems
}

DOI:

10.1109/TPEL.2017.2700898

\section{Document Version}

Accepted author manuscript

Link to publication record in Manchester Research Explorer

\section{Citation for published version (APA):}

Zhang, C., Lin, D., \& Hui, S. Y. R. (2017). Ball-Joint Wireless Power Transfer Systems. IEEE Transactions on Power Electronics, 33(1), 65-72. https://doi.org/10.1109/TPEL.2017.2700898

\section{Published in:}

IEEE Transactions on Power Electronics

\section{Citing this paper}

Please note that where the full-text provided on Manchester Research Explorer is the Author Accepted Manuscript or Proof version this may differ from the final Published version. If citing, it is advised that you check and use the publisher's definitive version.

\section{General rights}

Copyright and moral rights for the publications made accessible in the Research Explorer are retained by the authors and/or other copyright owners and it is a condition of accessing publications that users recognise and abide by the legal requirements associated with these rights.

\section{Takedown policy}

If you believe that this document breaches copyright please refer to the University of Manchester's Takedown Procedures [http://man.ac.uk/04Y6Bo] or contact uml.scholarlycommunications@manchester.ac.uk providing relevant details, so we can investigate your claim.

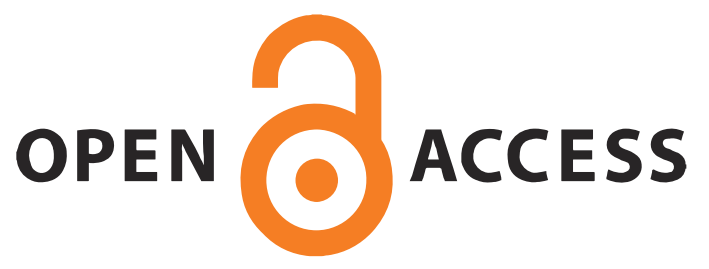




\title{
Ball-Joint Wireless Power Transfer Systems
}

\author{
Cheng Zhang, Student Member, IEEE, Deyan Lin, Member, IEEE, and S. Y. R. Hui, Fellow, IEEE
}

\begin{abstract}
A new wireless power transfer (WPT) system based on ball-joint structure is presented in this paper. A ball-joint WPT system consists of a ball structure with a mechanical rod attached to the ball and a ball socket that accommodate the ball structure. This ball-joint structure comprises at least one winding in the ball structure and at least one winding in the ball socket structure. The ball structure can be flexibly rotated over a wide range of angle inside the ball socket, while wireless power can still be transferred from the transmitter winding to the receiver winding through magnetic resonance. The magnetic coupling coefficient between the transmitter and receiver coil over a wide rotating angular range has been analyzed and experimentally checked. Experimental results confirm that an energy efficiency of up to $81 \%$ can be achieved.
\end{abstract}

Index Terms - wireless power transfer, ball-joint structure, magnetic resonance

\section{INTRODUCTION}

$\mathrm{W}$ ireless power transfer (WPT) based on the magnetic resonance and near-field coupling of two loop resonators was pioneered by Tesla, Hutin and Leblanc a century ago [1][2]. WPT can be radiative or non-radiative depending on the energy transfer mechanisms. Radiative (far-field) power can be emitted from an antenna and propagates through a medium (such as vacuum or air) over long distance (i.e. many times larger than the dimension of the antenna) in form of electromagnetic wave. However, due to the omni-directional nature of the radiative power emission, the energy efficiency of power transmission is very low. Far-field WPT is only suitable for applications (such as low-power sensor networks) in which efficiency is not a concern [3].

Non-radiative WPT relies on the near-field magnetic coupling of conductive loops and can be classified in the shortrange and the mid-range application contexts. Generally speaking, if the transmission distance is less than the diameter of the transmitter coil, the system is considered as short-range. Mid-range here refers to the applications in which the transmission distance is larger than the diameter of the transmitter coil and within a distance equivalent to a few multiples of the transmitter coil diameter. WPT has been applied extensively in ac machines, which were also pioneered by Tesla [4]. In a cage induction machine, for example, electric

C. Zhang is with the Department of Electrical Engineering, Massachusetts Institute of Technology, USA (e-mail:guszhang@mit.edu).

D. Lin is with the School of Automation, Wuhan University of Technology, Wuhan, and was with the Department of Electrical and Electronic Engineering, The University of Hong Kong, Pokfulam, Hong Kong (e-mail: deyanlin@whut.edu.cn; deyanlin@eee.hku.hk). energy is transferred from the stator windings across the air gap to the rotor cage. Wireless energy transfer via coupled windings is the basic principle used in electric machines. Another traditional WPT research topic is transcutaneous energy systems for medical implants (since 1960) [5-9] and induction heaters (since 1970) [10]. For modern short-range applications, the inductive power transfer (IPT) systems (since 1990) [11-15] and the wireless charging systems for portable equipment such as mobile phones (since 2000) [16-21] have attracted lots of attention. Wireless charging technology for portable electronic devices has reached commercialization stage through the launch of the "Qi" Standard by the Wireless Power Consortium [22], now comprising over 200 companies worldwide.

Several types of WPT techniques for mechanical systems with movable mechanical parts have been reported. In [23], a mechanical slip-ring with primary and seconding windings on the fixed and rotating parts is reported as shown in Fig.1. The primary winding is wound on the stationary (fixed) part of the machine. The secondary winding is wound on the motor shaft that can rotate. Note that the primary winding and the seconding windings share the same axis. This means that the two axes are fixed in one angle and cannot be changed in their relative mechanical angle. In this slip-ring arrangement, the relative positions of the primary and secondary windings remain the same regardless of the rotating speed of the motor shaft.

A second example is the use of a rotatory transformer with the transmitter and receiver windings placed on two sides of a rotational mechanical structure that also share the same rotational axis (Fig.2). Like the first example, the two windings are co-axial (i.e. sharing the same axis). Similar idea can be applied to a rotating system such as a radar system in which the coaxial primary and secondary windings are mounted on the stationary and rotating sides of the mechanical system (Fig.3). Another example can be found in [24].

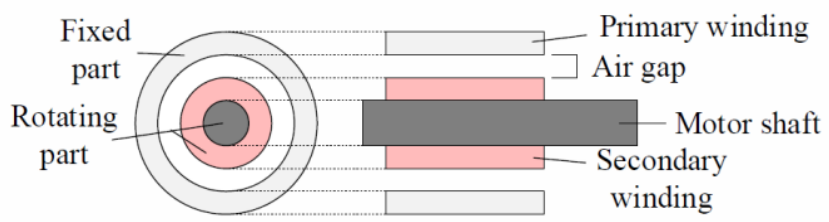

Fig.1 Example-1: Primary and Secondary Winding arrangement in a slip-ring structure [23]

S. Y. R. Hui is with the Department of Electrical and Electronic Engineering, Imperial College London, London SW7 2AZ, U.K., and also with the Department of Electrical and Electronic Engineering, The University of Hong Kong, Pokfulam, Hong Kong (e-mail: ronhui@eee.hku.hk). 


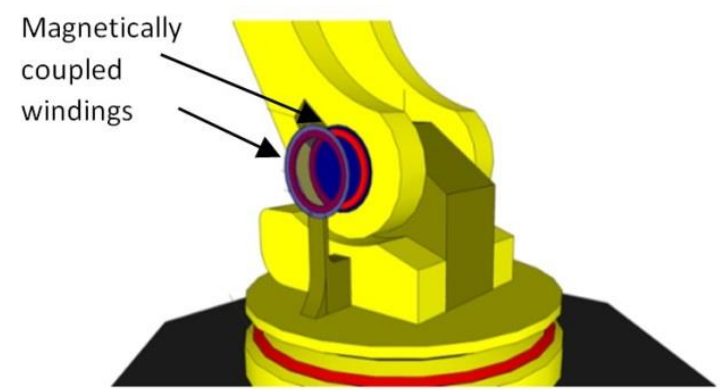

Fig.2 An example of two co-axial windings for wireless power transfer in a robotic arm.

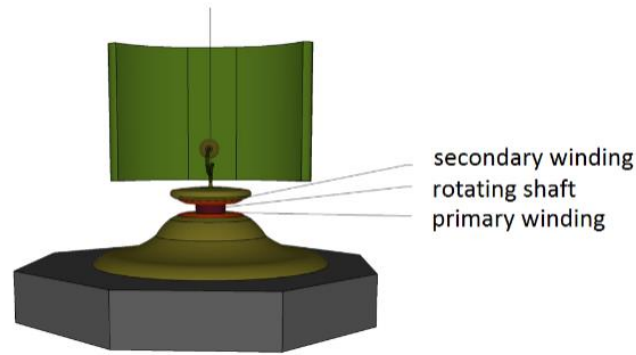

Fig.3 An example of two co-axial windings for wireless power transfer in a radar system.

A new concept of a WPT system based on a ball-joint structure is presented in this paper. Windings are embedded in the ball structure and ball-socket structure for WPT transfer purpose. A calculation method and an analysis of the mutual inductance over a wide angular range has been conducted. This proposed ball-joint WPT system has been practically constructed. Both theoretical and experimental results are presented to verify the proposal.

\section{THE BALL-JOINT WPT SYSTEMS}

This new idea of a ball-joint WPT system is illustrated in Fig.4. A mechanical stud has one end in the form of a ball structure, which is enclosed in a mechanical ball socket. This mechanical arrangement forms a ball-joint structure. The surface of the ball structure and that of the ball socket usually form a smooth contact with low friction so that the stud can be rotated to a wide range of angle in the ball joint structure. The friction in the contact surfaces should be low enough for the ball structure to be rotatable and yet sufficient to hold the ball structure once its position has been adjusted.

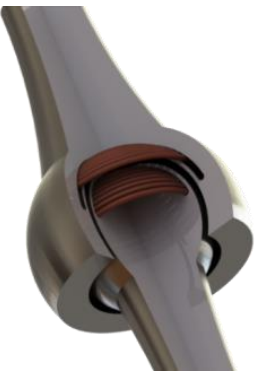

Fig.4 A view of the structure of the ball-joint WPT system with parts of the ball and ball-socket structures removed to show the embedded windings

There are several ways to embed the windings inside the ball and the ball-socket structures. Several winding examples for the ball structure are shown in Fig.5. In these cross-sectional diagrams, the cross-sections of the winding are highlighted. The cross-sections marked with a "cross" (X) refer to the current entering the plane under a certain excitation. Those marked with a "dot" $(\bullet)$ refer to current coming out of the plane. This representation is used to highlight the winding directions. In practice, high-frequency ac magnetic current flows through this winding and the actual current direction will change at operating frequency of the WPT system. Similarly, several examples of winding structures for the ball-socket structure are shown in Fig.6.

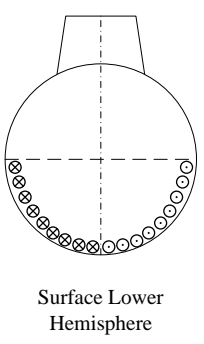

(a)

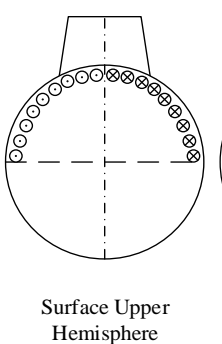

(b)

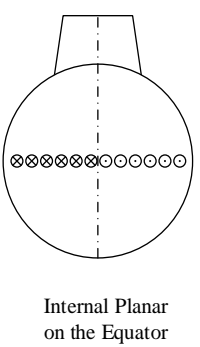

(c)

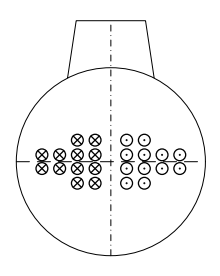

Internal Other

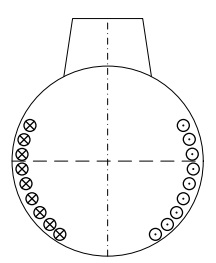

Surface Other

(e)
Fig.5 Several examples of WPT windings embedded inside the ball structure

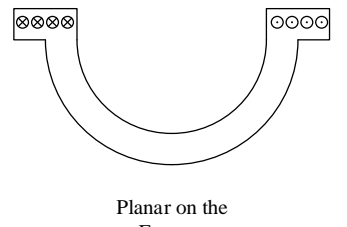

Equator

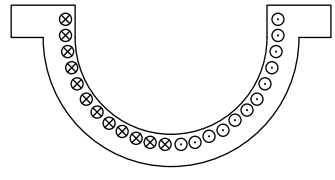

Surface

Hemisphere 
(a)

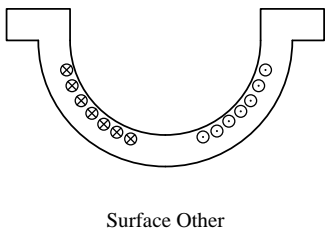

(c) (b)

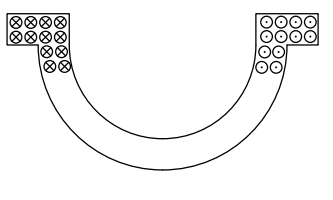

Others

(d)
Fig.6 Several examples of WPT windings embedded inside the ball-socket structure

In general, the two windings are magnetically coupled as shown in the equivalent circuit of an inductive WPT system in Fig.7. Usually, a capacitor is used in each coil (inductor) to form a resonant tank, because high energy efficiency can be achieved in WPT at magnetic resonance when the operating is at or near the resonance frequency of the resonant tank of the receiver. The power that can be transferred from the transmitter coil to the receiver coil is proportional to the operating frequency, mutual inductance between the transmitter (Tx) and receiver $(\mathrm{Rx})$ coils and the square of the transmitter coil current:

$$
P \propto f M I_{T x}^{2}
$$

where $M$ is the mutual inductance between Tx and Rx coils, $f$ is the operating frequency of the AC source, $I_{T x}$ is the current of the Tx coil excitation. The currents and voltages in the system can be calculated by the following equation

$$
\left[\begin{array}{c}
V_{T x} \\
0
\end{array}\right]=\left[\begin{array}{cc}
R_{T x}+j X_{T x} & j \omega M \\
j \omega M & R_{R x}+j X_{R x}
\end{array}\right]\left[\begin{array}{c}
I_{T x} \\
I_{R x}
\end{array}\right]
$$

where $R_{T X}$ is the total serial resistance of the transmitter circuit, $X_{T X}$ is the total serial reactance of the transmitter circuit and is equal to $\omega L_{T x}-\frac{1}{\omega C_{T x}}$ if the compensating capacitor is serially connected as illustrated in the above diagram. $R_{R x}$ and $X_{R x}$ are the parameters for the receiver circuit. $M$ is the mutual inductance between $\mathrm{Tx}$ and $\mathrm{Rx}$ coils. $I_{T x}$ and $I_{R x}$ are the currents flowing through the transmitter and receiver circuits. $V_{T X}$ is the AC voltage applied to the transmitter circuit.

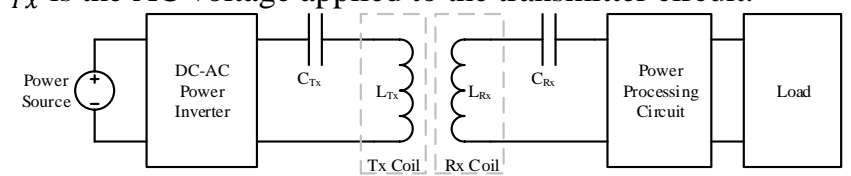

Fig. 7 Model of inductive coupling wireless power transfer.

\section{Modeling AND Optimal Winding Design Methods FOR BALL-JOINT WINDINGS WITH MINIMIZED VARIATION OF MUTUAL INDUCTANCE}

\section{A. Winding Structures}

Since the mutual inductance which affects the power transfer according to (1) may vary significantly in a ball-joint WPT structure, it is necessary to examine the winding design in order to minimize the fluctuation of mutual inductance between the two windings over a wide angular range. Considering the techniques of producing the ball joints, the most practical implementation is that the coils are winded around the surfaces of both ball structure and ball-socket structure. The symmetrical winding scheme can be defined by the parameters specified in Fig.8 and tabulated in Table I.

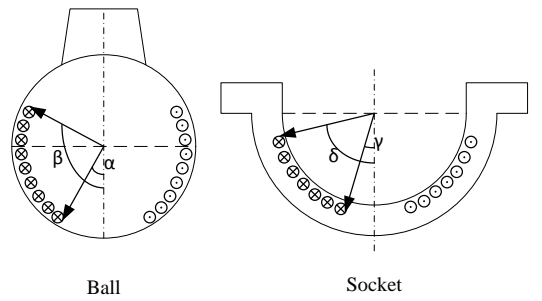

Fig.8 Diagrams of winding design with angular variables for optimization

TABLE I Parameters of Embedded Coils in Ball and Socket

\begin{tabular}{|c|c|c|}
\hline Parameter & Symbol & Unit \\
\hline Cross section radius of the wire & $\rho$ & $\mathrm{m}$ \\
\hline Interval between two turns of wire & $\Delta l$ & $\mathrm{~m}$ \\
\hline Number of turns & $\mathrm{N}$ & \\
\hline Ball winding starting angle & $\alpha$ & $\mathrm{deg}$ \\
\hline Ball winding ending angle & $\beta$ & $\mathrm{deg}$ \\
\hline Socket winding starting angle & $\gamma$ & $\mathrm{deg}$ \\
\hline Socket winding ending angle & $\delta$ & $\mathrm{deg}$ \\
\hline Ball winding radius & $r_{b}$ & $\mathrm{~m}$ \\
\hline Socket winding radius & $r_{S}$ & $\mathrm{~m}$ \\
\hline $\begin{array}{c}\text { Displacement angle between ball and } \\
\text { socket }\end{array}$ & $\theta$ & $\mathrm{deg}$ \\
\hline
\end{tabular}

To simplify the model, the following assumptions are made. Firstly, the winding in the ball socket covers not more than a hemisphere. Secondly, the coils are wounded symmetrically along the vertical axes in Fig.8. Due to symmetry of windings, only one displacement angle $\theta$ is needed to identify relative position between of the windings of the ball and the ball socket. Therefore

$$
\begin{aligned}
& 0<\alpha<\beta<180^{\circ} \\
& 0<\gamma<\delta<90^{\circ} \\
& 0<\theta<90^{\circ}
\end{aligned}
$$

where the angular variables $\alpha, \beta, \gamma, \delta$ and $\theta$ are specified in Fig.8.

\section{B. Modeling of Self- and Mutual-Inductance of unconventional windings}

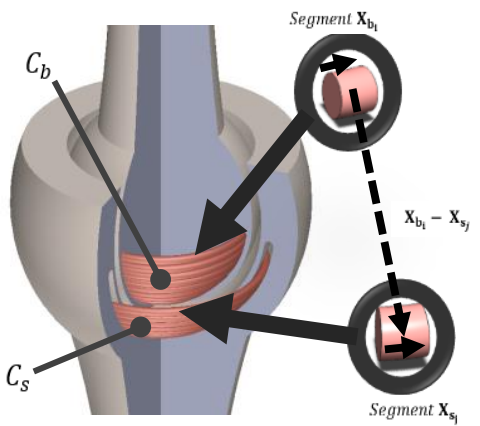


Fig.9 Irregular coils used in the ball-joint WPT system. Segment vectors on the ball coil and socket coil are illustrated.

Consider two arbitrary coils in Fig.9. The coils used in this application are irregular that it is difficult to derive the equation to calculate the self- and mutual- inductance values directly. The calculation is based on Neumann's formula.

$$
L_{m, n}=\frac{\mu_{0}}{4 \pi} \oint_{C_{m}} \oint_{C_{n}} \frac{\mathrm{d} \mathbf{X}_{\mathbf{m}} \cdot \mathrm{d} \mathbf{X}_{\mathbf{n}}}{\mathbf{X}_{\mathbf{m}}-\mathbf{X}_{\mathbf{n}}}
$$

where $L_{m, n}$ is the inductance between coil $m$ and coil $n$. Selfinductance is calculated when $m=n . \mu_{0}$ is the vacuum permeability if no magnetic material is used. $\mathbf{X}_{\mathbf{m}}$ and $\mathbf{X}_{\mathbf{n}}$ are infinitesimal length vectors along the coil $m$ and $n$. Practically, the denominator in the integral can be zero when calculating the self-inductance and when $\mathbf{X}_{\mathbf{m}} \equiv \mathbf{X}_{\mathbf{n}}$. At such situations, special handling techniques is required. The following equation given by Neumann [24] can be used to replace the partial element at the singularity.

$$
L_{p}=\frac{\mu}{2 \pi}\left[l \cdot \log \frac{l+\sqrt{l^{2}+\rho^{2}}}{\rho}-\sqrt{l^{2}+\rho^{2}}+\frac{l}{4}+\rho\right]
$$

where $l$ equals to the length of the discretized vector element of wire and $\rho$ is the radius of the cross section of the wire.

The trajectory of the ball and socket coils are generated and stored in vector arrays. Each segment in the array have the same length. Thus the value of $L_{p}$ is a fixed value.

$$
\begin{array}{r}
C_{b}=\left\{\mathbf{X}_{\mathbf{b}_{\mathbf{1}}}, \mathbf{X}_{\mathbf{b}_{\mathbf{2}}}, \ldots, \mathbf{X}_{\mathbf{b}_{\mathbf{n}}}\right\} \\
C_{s}=\left\{\mathbf{X}_{\mathbf{s}_{\mathbf{1}}}, \mathbf{X}_{\mathbf{s}_{2}}, \ldots, \mathbf{X}_{\mathbf{s}_{\mathbf{m}}}\right\} \\
M_{C_{b}, C_{S}}=\sum_{i=1}^{n} \sum_{j=1}^{m} \frac{\mu_{0}}{4 \pi} \frac{\mathbf{x}_{\mathbf{b}_{\mathbf{i}}} \cdot \mathbf{x}_{\mathbf{s}_{\mathbf{j}}}}{\mathbf{x}_{\mathbf{b}_{\mathbf{i}}} \mathbf{X}_{\mathbf{s}_{\mathbf{j}}}} \\
L_{C}=\sum_{i=1}^{n} \sum_{j=1}^{m}\left\{\begin{array}{cc}
\frac{\mu_{0}}{4 \pi} \frac{\mathbf{x}_{\mathbf{i}} \cdot \mathbf{x}_{\mathbf{j}}}{\mathbf{x}_{\mathbf{i}}-\mathbf{x}_{\mathbf{j}}} & i \neq j \\
L_{p} & i=j
\end{array}\right.
\end{array}
$$

\section{Optimal Design Method for Windings with Minimized Variation of Mutual Inductance}

With any given mechanical structure of ball joint, the radius of the inner and outer is determined, therefore the optimizable parameters are the four angular variables $\alpha, \beta, \gamma$ and $\delta$. Since the calculation equations are very complicated, genetic algorithm is used to find out the optimal values of start and end points of the coils. In order to minimize the variation of the mutual inductance over a wide angular movement of the ball structure within the ball socket, the mutual inductance values are calculated with a series of $\theta$ values. Assuming that the mutual inductance values at $K$ different angular positions are obtained, the mean value of the mutual inductance is:

$$
\mu_{M}=\frac{1}{K}\left(\left.M\right|_{\theta_{1}}+\left.M\right|_{\theta_{2}}+\cdots+\left.M\right|_{\theta_{K}}\right)
$$

The standard deviation of these $K$ inductance values is:

$$
S D=\sqrt{\frac{1}{K} \sum_{i=1}^{K}\left(\left.M\right|_{\theta_{i}}-\mu_{M}\right)^{2}}
$$

A fitness function is defined as:

$$
\text { fitness }(\alpha, \beta, \gamma, \delta)=\frac{\mu_{M}}{S D}+\mu_{M} * \mathrm{le}-6
$$

This fitness function is constructed to balance two factors: (1) to maximize the mutual inductance and (2) to minimize the fluctuation of the mutual inductance between the transmitter and receiver coils at different relative positions. The constant value $1 \mathrm{e}-6$ is an empirical parameter used to adjust the weighting of the two factors.

Genetic algorithm is adopted to optimize the objective function which is defined as:

$$
J(\alpha, \beta, \gamma, \delta)=\max [\text { fitness }(\alpha, \beta, \gamma, \delta)]
$$

\section{WPT WINDING DESIGNS AND PRACTICAL VERIFICATION OF BALL-JOINT WPT SYSTEMS}

Simulation and experiments have been carried out to evaluate the optimized solution. The physical dimensions of the ball joint are firstly determined. The ball coil radius is $4 \mathrm{~cm}$ and the socket coil radius is $5 \mathrm{~cm}$. The cross-section radius of the wire is $0.75 \mathrm{~mm}$. In this work, $\theta$ is selected from 0 to $\frac{\pi}{2}$ with $15^{\circ}$ interval. The displacement angles selected are: $0,15^{\circ}, 30^{\circ}, 45^{\circ}, \ldots, 75^{\circ}$, as most of the practical ball joints will have dead zones. In this study, the winding embedded in the ball socket is used as the transmitter coil, while that embedded in the ball as the receiver coil. The ball and ball-socket structures are fabricated with a 3D printer. The rotating angle of the ball structure in the socket is from 0 degree to about 90 degree.

\section{A. Standard Winding Design}

Fig.10(a) and (b) show two relative positions of the two windings embedded in the ball and ball-socket structures. The number of turns in the ball structure is $N_{R x}=33$ (red coil) and that in the ball socket is $N_{T x}=42$ (blue coil). The four angular parameters in this standard winding structure is tabulated in Table II. Based on the mutual inductance calculation explained in Section III, the mutual inductance values over a wide range of displacement angles are calculated based on (10) and plotted with the measured values in Fig.11. It is obvious that the mutual 
inductance value changes substantially from $33.4 \mathrm{uH}$ to $1.87 \mathrm{uH}$ when the displacement angle changing from 0 to 75 degree. While this inductance profile has high inductance value (and thus high energy efficiency in WPT), there is a certain angular range (e.g. from 60 degree to 90 degree) that the inductance value is very low. There is some small difference between the measured and simulated mutual inductance profile. This difference arises from the facts that the practical windings are not ideal and that airgap between the transmitter coil and receiver coil in the 3-D printed structure is not perfect. But the practical and simulated mutual inductance profiles are consistent.

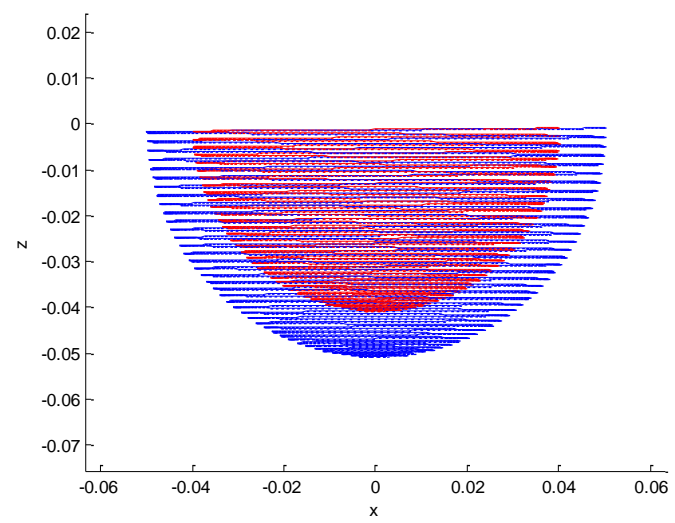

(a)

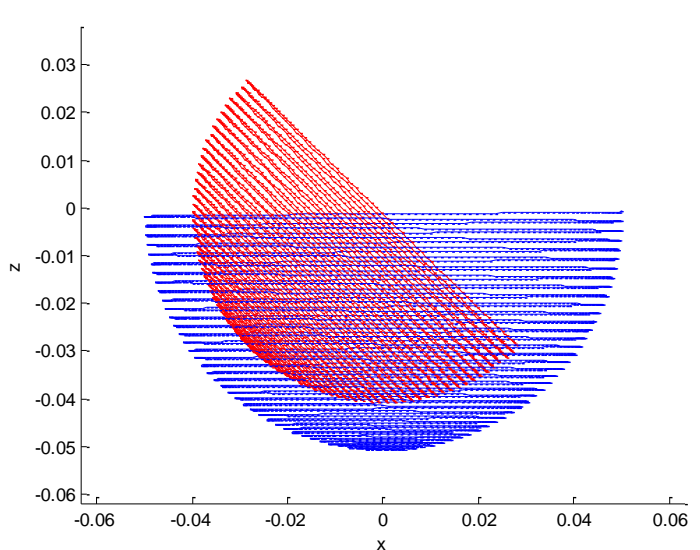

(b)

Fig.10 Relative positions of the transmitter coil (blue) and receiver coil (red) for $\alpha=0, \beta=90^{\circ}, \gamma=0$ and $\delta=90^{\circ}$ : (a) with no displacement angle; (b) with $45^{\circ}$ displacement angle

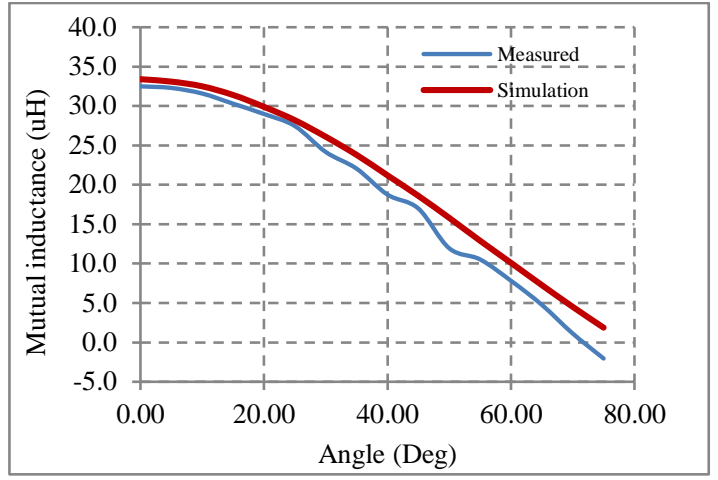

Fig.11 Calculated and measured mutual inductance vs. displacement angle of the between the two coils shown in Fig.10.

\section{B. WPT Winding Design with Minimized Variation in Mutual Inductance}

A second set of windings shown in Fig.12 are used for the design with minimized variation of mutual inductance. Same as the previous standard winding design, $\mathrm{NTx}=41$ (blue coil), $\mathrm{NRx}=14$ (red coil). For this GA-optimized winding design, the mutual inductance value has much less variation from 0 to $75^{\circ}$. It only varies from $10.8 \mathrm{uH}$ to $6.43 \mathrm{uH}$ when the displacement angle changing from 0 to $75^{\circ}$. The parameters of this hardware prototype are listed in Table IV. The four optimized parameters of the coil windings have been solved by the GA and are listed in TABLE III. The calculated mutual inductance values and the measured one are displayed in Fig.13.

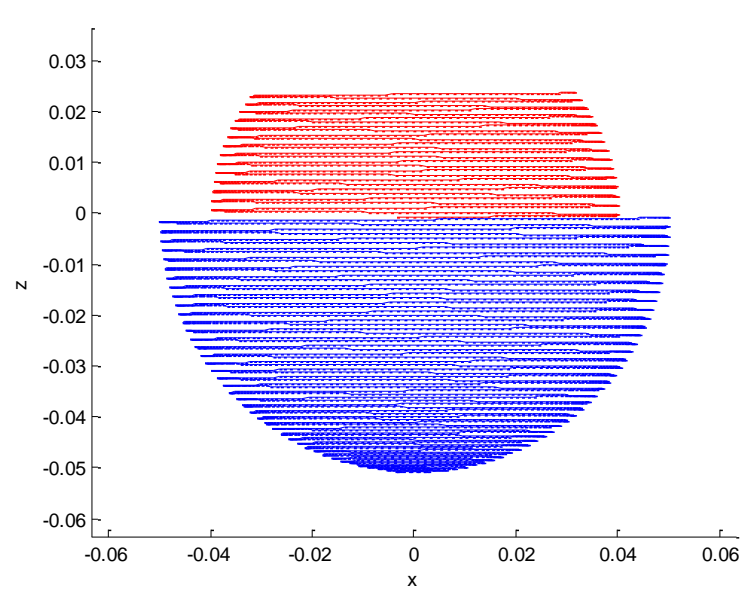

(a) 


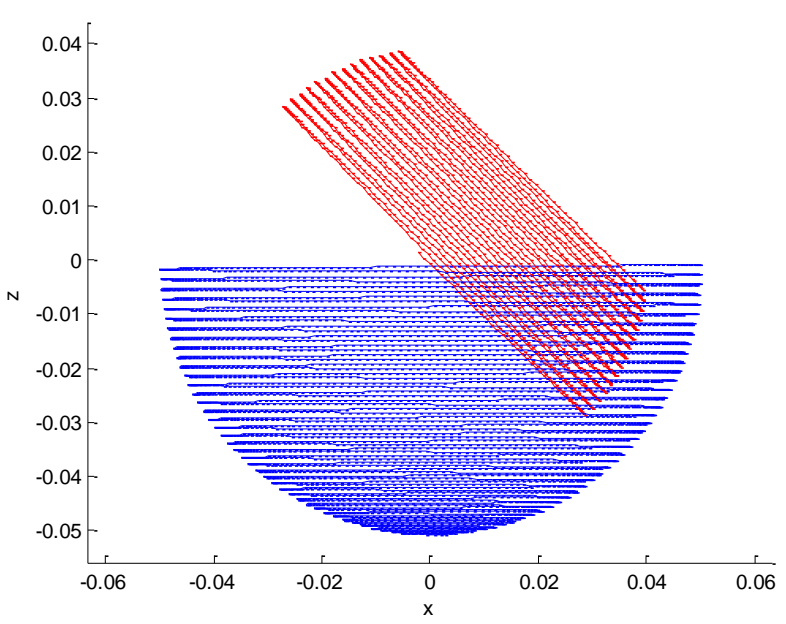

(b)

Fig.12 Relative positions of the transmitter coil (blue) and receiver coil (red) for $\alpha=45^{\circ}, \beta=127.8^{\circ}, \gamma=1.8^{\circ}$ and $\delta=90^{\circ}$ : (a) with no displacement angle; (b) with $45^{\circ}$ displacement angle

Table II Parameters for a Set of Standard Windings

\begin{tabular}{|c|c|}
\hline Parameter & Optimal value \\
\hline$\alpha$ & 0 \\
\hline$\beta$ & $90^{\circ}$ \\
\hline$\gamma$ & 0 \\
\hline$\delta$ & $90^{\circ}$ \\
\hline
\end{tabular}

TABLE III Optimized parameters by Genetic Algorithm

\begin{tabular}{|c|c|}
\hline Parameter & Optimal value \\
\hline$\alpha$ & $90^{\circ}$ \\
\hline$\beta$ & $127.8^{\circ}$ \\
\hline$\gamma$ & $1.8^{\circ}$ \\
\hline$\delta$ & $90^{\circ}$ \\
\hline
\end{tabular}

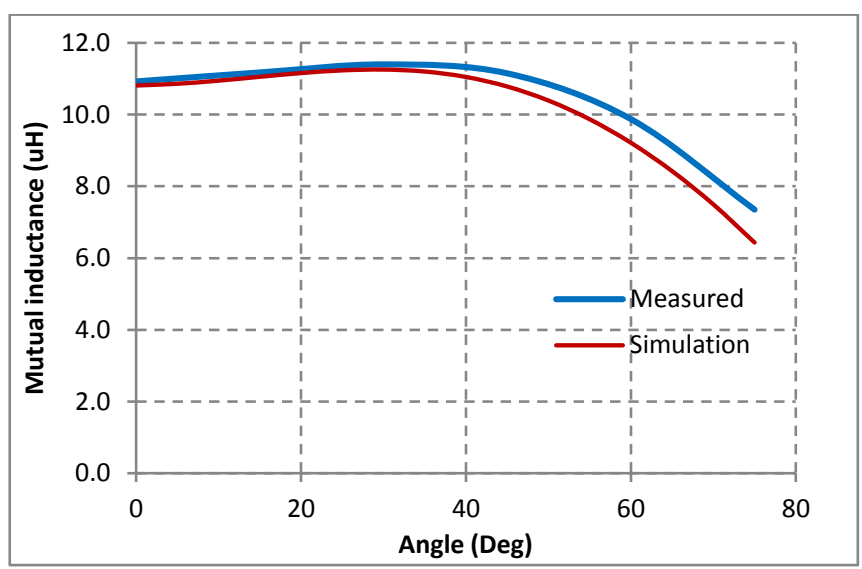

Fig.13 Calculated and measured mutual inductance vs. displacement angle of the between the two coils shown in Fig.12.

\section{Practical Verification}

The parameters are applied to a 3D-printed ball joint structure. The coils are wounded using litz wire with exactly the same parameters as the optimized results. Both coils are connected with series compensating capacitors in order to form resonant tanks with resonant frequency identical to the operating frequency. The receiver at the ball side is connected with an output load of $51 \Omega$ non-inductive resistor. The power source is a $10 \mathrm{~W}$ high-frequency sinusoidal voltage generator. Fig.14(a) and Fig.14(b) show two photographs of the ball-joint WPT system with the ball structure placed in two different positions. The energy efficiency has been measured for a wide angular range and is plotted in Fig. 15 and listed in Table V. The energy efficiency stays above $80 \%$ from 0 degree to 75 degree. Also an LED load is used in the receiver winding for demonstration as shown in Fig.16. The photographs show that the brightness of the LED load is similar in the two displacement angles.

TABLE IV Parameters of the Ball Joint

\begin{tabular}{|c|c|c|}
\hline Parameter & Unit & Value \\
\hline Ball coil radius & $\mathrm{cm}$ & 4 \\
\hline Socket coil radius & $\mathrm{cm}$ & 5 \\
\hline Load impedance & $\mathrm{Ohm}$ & 51 \\
\hline Ball coil self-inductance & $\mu \mathrm{H}$ & 18.3 \\
\hline Socket coil self-inductance & $\mu \mathrm{H}$ & 70.0 \\
\hline Operating frequency & $\mathrm{kHz}$ & 585 \\
\hline
\end{tabular}

TABLE V Measured Current, Voltage and Power Values at Different Displacement Angles

\begin{tabular}{|c|c|c|c|c|c|c|l|}
\hline $\begin{array}{c}\theta \\
(\mathrm{deg})\end{array}$ & $\begin{array}{c}V_{\text {in }} \\
(\mathrm{RMS}, \mathrm{V})\end{array}$ & $\begin{array}{c}I_{\text {in }} \\
(\mathrm{RMS}, \mathrm{A})\end{array}$ & $\begin{array}{c}P_{\text {in }} \\
(\mathrm{W})\end{array}$ & $\begin{array}{c}V_{\text {out }} \\
(\mathrm{RMS}, \mathrm{V})\end{array}$ & $\begin{array}{c}I_{\text {out }} \\
(\mathrm{RMS}, \mathrm{A})\end{array}$ & $\begin{array}{c}P_{\text {out }} \\
(\mathrm{W})\end{array}$ & Efficiency \\
\hline 0 & 11.71 & 0.34 & 3.93 & 13.65 & 0.25 & 3.37 & $85.73 \%$ \\
\hline 15 & 11.88 & 0.33 & 3.93 & 13.67 & 0.25 & 3.38 & $86.04 \%$ \\
\hline 30 & 12.06 & 0.33 & 3.93 & 13.68 & 0.25 & 3.38 & $86.01 \%$ \\
\hline 45 & 11.73 & 0.34 & 3.97 & 13.71 & 0.25 & 3.41 & $85.78 \%$ \\
\hline 60 & 10.57 & 0.38 & 3.99 & 13.66 & 0.25 & 3.38 & $84.66 \%$ \\
\hline 75 & 7.73 & 0.48 & 3.60 & 12.76 & 0.23 & 2.94 & $81.60 \%$ \\
\hline
\end{tabular}




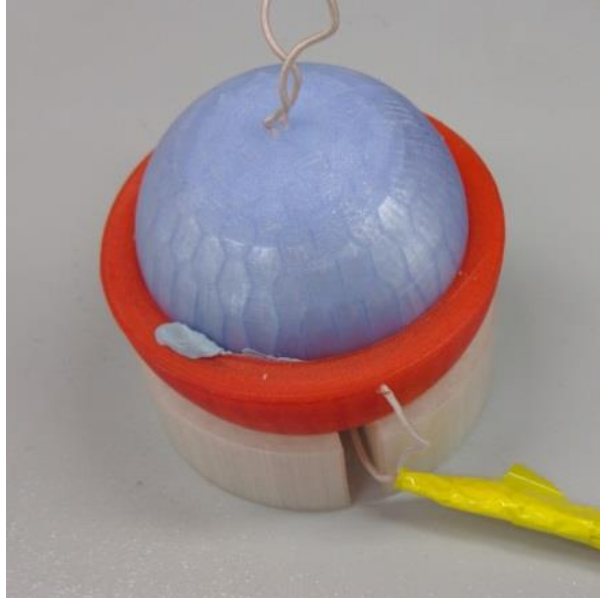

(a)

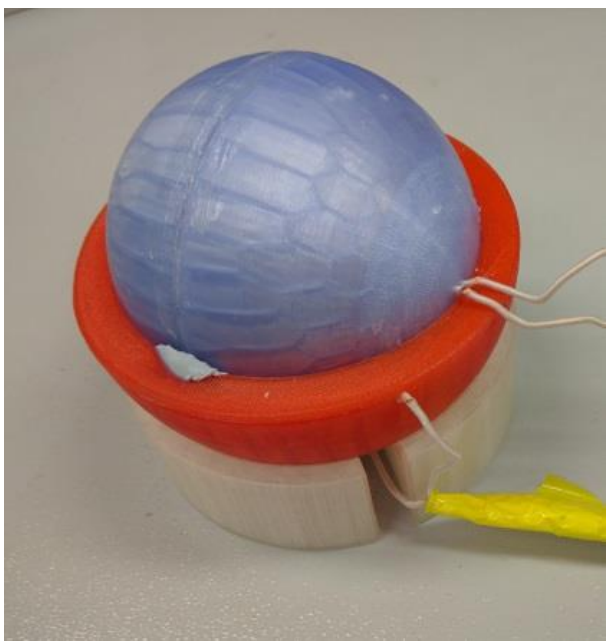

(b)

Fig. 14 Photographs showing the ball-joint WPT system with the ball structure (loaded with a non-inductive resistor) and placed in two different positions

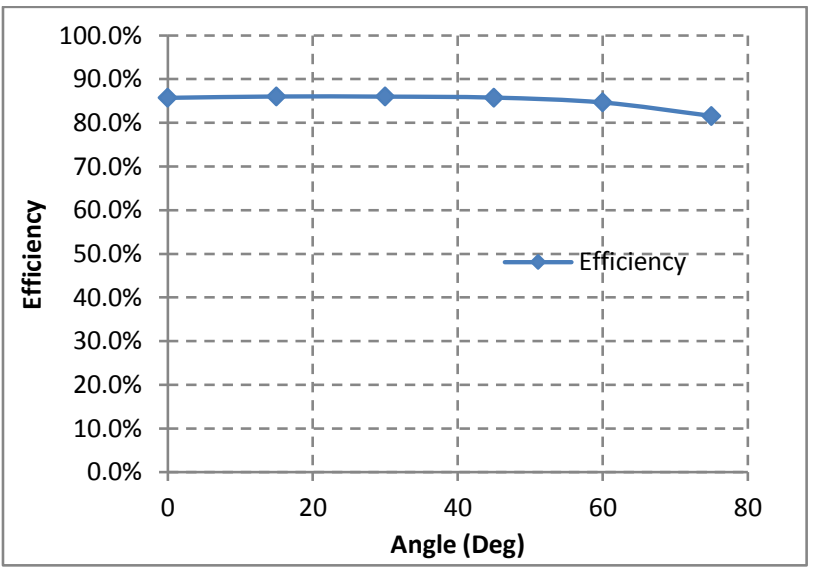

Fig.15 Measured energy efficiency with displacement angle

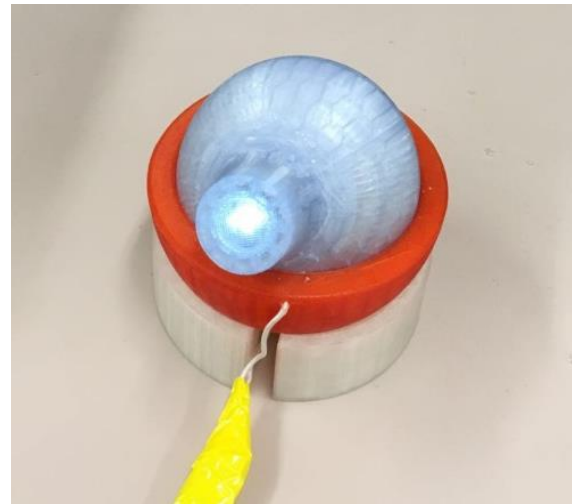

(a)

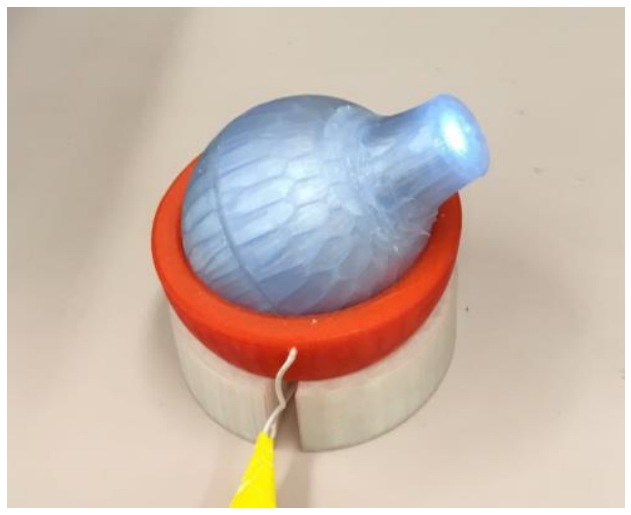

(b)

Fig. 16 The ball-joint WPT system with the ball structure loaded with highbrightness light-emitting diode and placed in two different positions

\section{CONCLUSION}

A novel concept of ball-joint WPT systems is presented in this paper. This preliminary study shows that standard and nearoptimized winding designs exhibit different mutual inductance profiles. The near-optimized winding design not only reduces the variation of the mutual inductance but also enables high energy efficiency well above $80 \%$ to be maintained over wide range of angular displacement. This new proposal has been practically verified with a hardware prototype fabricated with a $3 \mathrm{D}$ printer. Further work is needed to investigate a variety of the optimal dimensions of such ball-joint WPT structures in view of the possibilities of higher switching frequency and lowloss winding designs. In addition, the application potential of multiple WPT ball-joints and rotary joints in robotics should be explored. (Note: A video on the demonstration of this preliminary study is included as supplementary material.)

\section{ACKNOWLEDGMENT:}

C. Zhang and S.Y.R. Hui are grateful to the University of Hong Kong for its support for the patent application [26].

\section{REFERENCES}

[1] N. Tesla, "Apparatus for transmitting electrical energy," U.S. Patent 1,119,732, Dec. $1,1914$. 
[2] S.Y.R. Hui, "Magnetic Resonance for Wireless Power Transfer [A Look Back], IEEE Power Electronics Magazine, Vol. 3, Issue:1, 2016, pp: 1431

[3] J. Garnica, R.Chinga and Jenshan Lin, "Wireless power transmission: From far field to near field", Proceedings of the IEEE, Vol.101, No.6, June 2013, pp: 1321-1331

[4] Robert Lomas, The man who invented the twentieth century - Nikola Tesla - Forgotten Genius of Electricity. Headline 1999, ISBN 07472 62659 , p. 146

[5] J. C. Schuder, H. E. Stephenson, and J. F. Townsend, "High level electromagnetic energy transfer through a closed chestwall," IRE Int. Conv. Rec., pt.9, vol.9, pp. 119-126, 1961

[6] W. H. Ko, S. P. Liang, and C.D.F. Fung, "Design of rf-powered coils for implant instruments," Med. Biol. Eng. Comput., vol. 15, pp. 634-640, 1977.

[7] E. Hochmair, "System optimization for improved acuracy in transcutaneous signal and power transmission", IEEE Trans. Biomedical Engineering, vol. BME-31, no.2, pp. 177-186, Feb. 1984.

[8] B. Choi, J. Nho, H. Cha, T. Ahn and S. Choi, "Design and implementation of low-profile contactless battery charger using planar printed circuit board windings as energy transfer device," IEEE Trans. Industrial Electronics, vol. 51, no. 1, pp. 140-147, Feb. 2004.

[9] Y. Jang and M. M. Jovanovic, "A contactless electrical energy transmission system for portable-telephone battery chargers", IEEE Trans. Industrial Electronics, vol. 50, no. 3, pp. 520-527, Jun. 2003.

[10] W.G. Hurley and J. Kassakian, "Induction heating of circular ferromagnetic plates", IEEE Trans. Magnetics, vol. 15, no. 4, pp. 11741181, Jul. 1979.

[11] A.W. Green and J.T. Boys, " $10 \mathrm{kHz}$ inductively coupled power transferconcept and control", in Proc. ICPE-VSD, 1994, pp. 694-699.

[12] J.T. Boys, G.A. Covic and A.W. Green, "Stability and control of inductively coupled power transfer systems", in Proc. Electric Power Applications, 2000, vol. 147, no. 1, pp. 37-43.

[13] J.T. Boys, A.P. Hu and G.A. Covic, "Critical Q analysis of a current-fed resonant converter for ICPT applications", Electronics Letters, vol. 36, no. 17, pp. 1440-1442, 2000.

[14] G.A.J. Elliott, G.A. Covic, D. Kacprzak and J.T. Boys, “A New Concept: Asymmetrical Pick-Ups for Inductively Coupled Power Transfer Monorail Systems", IEEE Trans. Magnetics, vol. 42, no. 10, pp. 3389 3391, 2006.

[15] M.L.G. Kissin, J.T. Boys and G.A. Covic, "Interphase Mutual Inductance in Polyphase Inductive Power Transfer Systems", IEEE Trans. Industrial Electronics, vol. 56, no. 7, pp. 2393-2400, 2009.

[16] B. Choi, J. Nho, H. Cha, T. Ahn and S. Choi, "Design and implementation of low-profile contactless battery charger using planar printed circuit board windings as energy transfer device", IEEE Trans. Industrial Electronics, vol. 51, no. 1, pp. 140-147, Feb. 2004.

[17] Y. Jang and M. M. Jovanovic, "A contactless electrical energy transmission system for portable-telephone battery chargers", IEEE Trans. Industrial Electronics, vol. 50, no. 3, pp. 520-527, Jun. 2003.

[18] C.-G. Kim, D.-H. Seo, J.-S. You, J.-H. Park and B. H. Cho, "Design of a contactless battery charger for cellular phone", IEEE Trans. Industrial Electronics, vol. 48, no. 6, pp. 1238-1247, Dec. 2001

[19] S.Y.R. Hui and W.C. Ho, "A new generation of universal contactless battery charging platform for portable Consumer Electronic equipment", IEEE Trans. Power Electronics, vol. 20, no. 3, pp. 620-627, May 2005.

[20] X. Liu and S.Y.R. Hui, "Simulation Study and Experimental Verification of a Contactless Battery Charging Platform with Localized Charging Features" IEEE Trans. Power Electronics, vol. 22, no.6, pp. 2202-2210, Nov. 2007.

[21] S.Y.R. Hui, "Planar Inductive Battery Charging System", US Patent 7,576,514, 2009.

[22] Wireless Power Consortium Website [online]. Available: http://www.wirelesspowerconsortium.com

[23] Yeongrack Son and Jung-Ik Ha, "The Electric Variable Transmission without Slip Ring for the Hybrid Electric Vehicle Driving Structure", 9th International Conference on Power Electronics-ECCE Asia, June 1 - 5, 2015, Convention Center, Seoul, Korea

[24] Pekka Eskelinen, "Experimental Rotary Transformers For Antenna Power Supplies and Control", IEEE Antennas and Propagation Magazine, Vol. 52, No.5, October 2010, 165-167

[25] E. B. Rosa and L. Cohen, "Formulae and Tables for the Calculation of Mutual and Self-inductance," Bulletin of the Bureau of Standards, vol. 5, pp. 35-50, 1907.
[26] S.Y.R. Hui and C. Zhang, "Ball and Socket Wireless Power Transfer Systems", Patent application PCT/CN2016/106366, filed 18 Nov., 2016

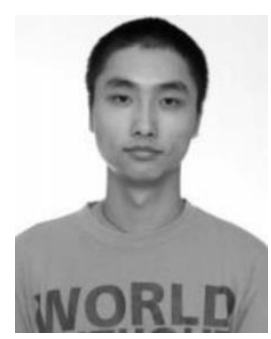

Cheng Zhang was born in China, in 1990. He received the B.Eng. degree with first class honors in electronic and communication engineering from the City University of Hong Kong, Kowloon, Hong Kong SAR, in 2012, and received Ph.D. degree in the Department of Electrical and Electronic Engineering, The University of Hong Kong, Pokfulam, Hong Kong. $\mathrm{He}$ is currently a Postdoctoral Fellow with the Department of Electrical Engineering, Massachusetts Institute of Technology, USA.

His current research interests include designs and optimizations for wireless power transfer applications.

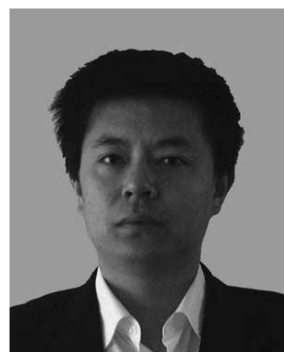

Deyan Lin (M'09) received the B.Sc. and M.A.Sc. degrees from Huazhong University of Science and Technology in 1995 and 2004, respectively, and the Ph.D. degree from the City University of Hong Kong in 2012.

$\mathrm{He}$ is currently a professor with the School of Automation, Wuhan University of Technology, Wuhan, and was a Post-doctoral Fellow with the Department of Electrical and Electronic Engineering, The University of Hong Kong. From 1995 to 1999, he was a Teaching Assistant in the Electrical Engineering Department at Jianghan University, Wuhan, where he became a Lecturer in 1999. From 2008 to 2009, he was a Senior Research Assistant with the City University of Hong Kong. His current research interests include wireless power transfer, memristors, modeling and control of gasdischarge lamps and light-emitting diode technology.

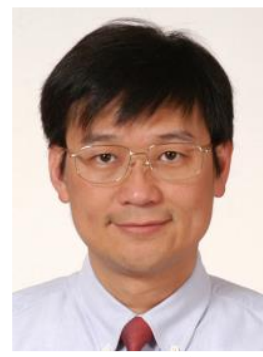

S. Y. Ron Hui (M'87-SM'94-F'03) received his BSc (Eng) Hons at the University of Birmingham in 1984 and a D.I.C. and $\mathrm{PhD}$ at Imperial College London in 1987. Presently, he holds the Philip Wong Wilson Wong Chair Professorship at the University of Hong Kong and a part-time Chair Professorship at Imperial College London.

$\mathrm{He}$ has published over 300 technical papers, including more than 200 refereed journal publications. Over 60 of his patents have been adopted by industry. $\mathrm{He}$ is an Associate Editor of the IEEE Transactions on Power Electronics and IEEE Transactions on Industrial Electronics, and an Editor of the IEEE Journal of Emerging and Selected Topics in Power Electronics. His inventions on wireless charging platform technology underpin key dimensions of Qi, the world's first wireless power standard, with freedom of positioning and localized charging features for wireless charging of consumer electronics. In Nov. 2010, he received the IEEE Rudolf Chope R\&D Award from the IEEE Industrial Electronics Society and the IET Achievement Medal (The Crompton Medal). He is the recipient of the 2015 IEEE William E. Newell Power Electronics Award. He is a Fellow of the Australian Academy of Technology \& Engineering and a Fellow of the Royal Academy of Engineering, U.K. 